\title{
"THE NATURE OF THE AQUEOUS HUMOUR"*
}

\author{
BY \\ J. Douglas Robertson \\ LONDON .
}

IN a recent issue of this Journal (Vol. XXI, p. 577), Duke-Elder has raised several points in criticising my paper concerning the theories on the formation and exit of the aqueous humour.

1. The canal of Schlemm.-Duke-Elder has written (Brit. Jl. Ophthal., Vol. XXI, p. 578)-“" the essential feature which enables this structure to function as a preferential drain for fluids in the eye is that while it (like the capillaries) has an endothelial wall through which fluid traffic can take place, it. . . must have a pressure considerably less than the capillaries. It is thus a capillary (in the physiological not the anatomical sense) in the venous system."

Under normal pressure conditions within the eye, it is generally believed that the intra-ocular pressure exceeds the pressure in the canal of Schlemm, but as no-one has ever measured the capillary pressure nor that in the canal of Schlemm, it has not been proved as Duke-Elder asserts that the pressure in the canal of Schlemm is considerably less than the capillary pressure. Indeed, it is probable that the pressures within these vessels may not be static. For in the case of the capillaries, the work of Rous and his associates suggests that the attractive conception of a circulation of fluid through the tissues with filtration at the arterial end of the capillary and absorption at the venous end may not be true. They believe that the capillaries throughout their entire length are either producing filtrate or absorbing fluid, so that the hydrostatic capillarÿ pressure at one time exceeds the colloid osmotic pressure of the plasma and at another time is less than it. That the interchange of fluid within the eye is not governed by such a law is apparent when an increase in intra-ocular pressure takes place if only the exit at the canal of Schlemm is blocked (the canal of Schlemm only forms a small part of the whole surface of the eye).".

If the pressure in the canal of Schlemm exceeds the intraocular pressure, why does fluid not enter the chamber from the canal? There is no evidence that it does so. It may be argued that by reason of the alleged protein rich fluid within the canal of Schlemm an osmotic force comes into play. But the fact remains as I have pointed out (Brit. Jl. Ophthal., Vol. XXI, p. 444); if the canal of Schlemn could attract fluid from the anterior

* From the Courtauld Institute of Biochemistry, Middlesex Hospital, London, W.1 
chamber by osmosis, it must do so by reason of its protein content, and this in the capillary is provided for by the plasma. Normally, no red cells have been observed in the canal of Schlemm and this strongly suggests that the canal of Schlemm does not conform to the requirements of a capillary and thus cannot play any part as such in the interchange of fluid by osmosis. A vessel which (a) permits fluid traffic in one direction only, (b) does not normally contain red cells, and (c) begins as a cul-de-sac (i.e., there is no afferent vessel) and enters the venous system, is not a vascular capillary in any sense physiological or anatomical as Duke-Elder has written. Venous capillaries, or more correctly, sinusoid vessels (examples of which are found in the liver) have a relationship to the vascular system in no way different from that of the other capillaries throughout the body except that in this case the afferent vessel of the capillary is a vein and not an artery.

2. The chemical equilibrium.-The analyses on sodium and chloride which have been carried out by many workers and most recently by Duke-Elder and his colleagues, are such that the equilibrium between aqueous humour and blood may be explained by the Donnan theory. But it is agreed at the same time that the distribution of other electrolytes and non-electrolytes such as phosphate, sulphate, uric-acid, urea and sugar are not in accord with the Donnan theory. Of the many constituents analysed by Walker which I quoted, Duke-Elder has selected urea for closer study. He points out that the method employed by Walker was not so accurate as that described by Ranganathan and Sastri (Biochem. Jl. Vol. XXX, p. 2,135) and employed by Benham (Biochem. Jl.. Vol. XXXI, p. 1,157) in a study of the aqueous and serum from the same animal. A Although the conductometric method would appear to be more accurate, it is not so accurate as DukeElder suggests. In the original paper of Ranganathan and Sastri this method is stated to be accurate to 1 per cent. using $0.1 \mathrm{ml}$. of blood as compared with the aeration titration method stated to be accurate to 1 per cent. using $3 \mathrm{ml}$. blood, but divergencies up to 4 per cent. are recorded for the above methods applied blood and urine using larger quantities than stated above. Duke-Elder then makes the following statement. "The passage of four years has changed a variation of 49 to 95 with an average of 68 per cent. (Walker's results in $J l$. Biol. Chem., Vol. CI, p. 269) to a variation of 80.5 to 95.7 with an average of 90 per cent. (Benham's results in Biochem. Jl., Vol. XXXI, p. 1,157). What will the next four years bring? I am far from claiming finality from Benham's method." Prophetic utterances are, I think, out of place in a scientific publication but one feels tempted to reply that by excluding the analysis of Walker and others and confining the study of the urea equilibrium solely to the analyses carried out 
by Duke-Elder and his collaborators one finds in 1927 (Biochem. Jl., Vol. XXI, p. 66), the urea of the aqueous and blood agree to within 3 per cent., and in 1936 (Biochem. Jl., Vol. XXXI, p. $1,157)$, the average of seven analyses of the aqueous and the blood agreed to 10 per cent. Thus it would appear that the passage of nine years has caused a disparity of 3 per cent. to become one of 10 per cent. Therefore, the passage of the next four or nine years may well prove interesting.

The main facts of scientific interest, however, borne out by Benham's results are that they confirm Walker's findings and refute those of Duke-Elder (Biochem. Jl., Vol. XXI, p. 66, and Brit. Jl. Ophthal., 1927, Monograph Supp. II). Both Walker and Benham found that the concentration of urea in the aqueous humour was less than that in the blood and as urea is freely dialysable in vivo and in vitro it follows that the aqueous humour is not produced by the process of dialysis. If the aqueous humour

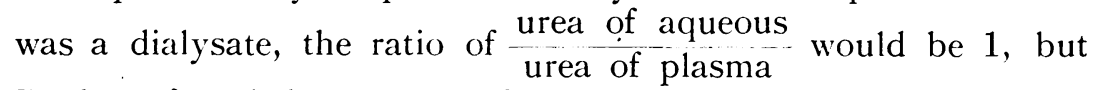
Benham found the average of his seven cases to have a ratio of 0.9 and what is of greater importance, the range of his results was less than $1-(0.805$ to $0.95 \%)$.

Duke-Elder found that sugar was partitioned in approximately equal amounts (Biochem. Jl., Vol. XXI, p. 66). The question of the concentration of sugar in the aqueous has now reached a very interesting phase in view of recent work upon the high concentration of ascorbic acid in the aqueous. This substance is a very strong reducing agent and Müller (Nature, Vol. CXXXII, p. 280), has found its concentration in the aqueous is possibly as high as $18 \mathrm{mgs}$. per $100 \mathrm{ml}$., while less than $1 \mathrm{mg}$. per $100 \mathrm{ml}$. is present in blood serum. My colleague Mr. J. Barrett (unpublished results) has found by employing the Hagedorn-Jensen or Shaffer-Hartman method that a concentration of $18 \mathrm{mgs}$. per 100 $\mathrm{ml}$. of ascorbic acid had a reducing power as glucose of almost $13.5 \mathrm{mg}$. per $100 \mathrm{ml}$. Thus when a correction is made for the presence of ascorbic acid in the aqueous, it becomes necessary to state that less sugar is present in aqueous than blood.

3. The osmotic equilibrium.-Duke-Elder's most recent method of determining the osmotic pressure of the aqueous humour ( $J l$. Physiol., Vol. LXXXIX, p. 61) merely corroborates his previous results. The point $I$ made in my paper which Duke-Elder says he is unable to follow is more simply this. The aqueous humour is isotonic with blood, and so also is lymph, cerebrospinal fluid, gastric juice, pancreatic juice and hepatic bile. Osmotic pressure observations therefore, by any method, are of no value in determining whether a fluid is a secretion and not a dialysate or vice versa. 
4. The experimental work on the maintenance of the intra-ocular pressure.-There is no need for me to repeat the results of my investigations into Duke-Elder's experimental work. Suffice it to say that in most of the experiments he recorded including what he considered a control (the injection of normal saline intravenously in an intact animal) the level of the intra-ocular pressure was not at any point in the experiment in accord with the theory of dialysis although he felt satisfied, at that time, that the correct answer had been obtained. Even his explanation (Brit. Jl. Ophthal., Vol. XXI, p. 583), that " such analyses as they will bear, however, brings out one point of extreme importance, that, in comparison with tissue fluids, there is a definite time lag in the reaction of the eye," is not sufficient, for in his control experiment (Brit. Jl. Ophthal., Vol X, p. 9, fig. 1), where a time lag was necessary the intra-ocular pressure did not alter. From DukeElder's own experiments along with my own observations on the intra-ocular pressure in oedematous nephritis, it may be said that a physical equilibrium does not exist between blood and aqueous, and the equilibrium level of the intra-ocular pressure is not maintained by the hydrostatic force in the capillaries minus the difference in osmotic pressure between aqueous and blood.

\section{Conclusions}

1. The canal of Schlemm is not a vascular capillary in any sense physiological or anatomical.

2. A further study of the urea and sugar equilibrium shows that the aqueous humour cannot be formed by dialysis because :-

a. The concentration of urea in the aqueous is lower than that in the blood.

b. The concentration of sugar in the aqueous is lower than that in the blood.

3. As secretions and dialysates are both isotonic with blood osmotic pressure observations are of no value in differentiating the one from the other.

4. A physical equilibrium does not exist between blood and aqueous, and the equilibrium level of the intra-ocular pressure is not maintained by the hydrostatic force in the capillaries minus the difference in osmotic pressure between blood and aqueous.

This is a further argument against the theory of dialysis.

\section{Summary}

In summary it may be stated that the observations which I reported originally refute the suggestion that the aqueous humour is a dialysate and Duke-Elder's most recent contribution does not cause me to alter this view. 